\title{
Articles
}

\section{Antitumor Activity of LB42907, a Potent and Selective Farnesyltransferase Inhibitor: Synergistic Effect in Combination with Other Anticancer Drugs}

\author{
Ji Hyun Park, Sun-Young Koo, Dong-Myung Kim, Kwihwa Kim, Shin Wu Jeong, Hyun-Ho Chung, \\ Heung-Soo Cho, Joonghoon Park, Hyeon Joo Yim, Jinho Lee, Jong Sung Koh, and Semi Kim*, \\ LG Life Sciences, Ltd R\&D Park, Yuseong-gu. Daejeon 305-380. Korea. ${ }^{\star}$ E-mail: semikimäalgls.co.kr \\ Received April 27, 2008
}

\begin{abstract}
Inlibitors of farnesyltransferase (FT), a key enzyme in the post-translational modifications of Ras proteins. have been extensively studied as novel anticancer agents in the preclinical stages. some of which are currently in clinical development. Previously. it has been reported that a novel FT inlibitor LB 42907 inhibits Ras farnesylation in the nanomolar range in vitro. The aim of this study was to assess the antitumor efficacy of LB+2907 in vitro and in wivo. Anchorage-independent growth of various human tumor cell lines was potently inhibited by treatment with LB+2907, comparable to other FT inhibitors in clinical development. In the nude mouse. oral administration of LB 42907 demonstrated potent antitumor activity in several human tumor xenograft models including bladder, lung and pancreas origin. Interestingly, significant tumor regression in EJ (bladder) and A5+9 (lung) xenografts was induced by LB 42907 treatment. The effectiveness of LB 42907 was also investigated in simultaneous combination with paclitaxel, vincristine. cisplatin or gemcitabine against NCI-H 460 . A549, and HCT1 16 cells in witro using median-effect analysis. LB 42907 markedly synergized with most anticancer drugs tested in this study in NCl-H 460 cell. In contrast. LB 42907 displayed antagonism or partial synergism with these drugs in A549 and HCT1 16 cells. depending on the class of combined drugs and/ or the level of cytotoxicity. Our results demonstrate that LB +2907 is an effective antitumor agent in vitro and in wio and combination of LB 42907 with other chemotherapeutic drugs results in synergistic or antagonistic effects mainly in a cell line-dependent manner. Further preclinical study is warranted.
\end{abstract}

Key Words : Farneșyltransferase inhibitor. LB42907. Antitumor activity. Xenograft. Combination effect

\section{Introduction}

Oncogenic mutations in ras genes (H-ras. N-ras. and $\mathrm{K}$ ras) occur in $\sim 30 \%$ of all human cancers. and in up to $50 \%$ of colon cancers and $40 \%$ of non-small cell lung cancers (NSCLC). ${ }^{1,2}$ Ras proteins associate to the inner plasma membrane and initiate several intracellular signaling pathways mediating cell proliferation and differentiation by functioning as a molecular switch. altennating between an inactive GDP-bound and an active GTP-bound state in a highly regulated way. However. oncogenic ras mutations impair the switch function. which results in the constitutive activation of the Ras proteins and subsequent downstream signaling effectors. This leads to unregulated cellular proliferation and transformation. ${ }^{3}$

Intracellular signaling event induced by Ras protein is dependent on its proper plasma membrane localization. ${ }^{4}$ This localization is supported by a series of post-trans-

Abbreviations: FT. farnesyltransferase: GGT I. geranylgeranyl transferase I: IC. inhibitory concentration: DMSO. dimethyl sulfoxide: CI. combination index: SRB, sulforhodamine B: NSCLC. non-small cell lung cancer

"Current address: Korea Research Institute of Bioscience and Biotechnology. Yusong-gu, Daejeon 305-806. Korea. semikimiakribb.re.kr lational modifications. the first and most important step of which is the fanesylation of the cysteme residue at the C. terminal CAAX sequence of the Ras protein. This reaction is catalyzed by farnesyltransferase (FT). Therefore, prevention of Ras protein localization to plasma membrane via FT inhibitors was regarded as a potentially effective mechanism for interfering with the Ras oncogenic pathway and preventing tumor growth, and thus FT inhibitors were initially developed as an anticancer drug to specifically target Ras. ${ }^{6}$ However. it has been recently discovered that FT inhibitors might act by more complex mechanisms involving $\mathrm{RhoB}$, centromere-associated proteins CENP-E and CENP-F. and other farnesylated proteins in addition to the Ras protein? suggesting that FT inhibitors might have the potential to function in multiple ways as anticancer agents.

Specific inhibitors of FT have been generated and extensively studied as novel anticancer agents. Preclinical studies indicate that these agents perform a broad spectrum of antitumor activities. including blocking cell proliferation and inducing apoptosis. Several lead compounds. such as SCH66336 and R115777. are currently in clinical development. ${ }^{8,9}$ Evidence for clinical anticancer efficacy has been reported, with dose-limiting toxicities, varying from myelosuppression, gastrointestinal tract toxicity, and neuropathy. 
To increase the therapentic index. a combination strategy of FT inhibitor with other diverse anticancer therapies is promising, so a number of preclinical and clinical combination studies are currently underway. ${ }^{\cdot 12}$

Lee $e t a l^{1 \hat{3}}$ have reported a novel class of pyrrole-based FT inhibitors. Several derivatives were orally active, with potent and selective inhibitors active in low or sub-nanomolar ranges in vitro. ${ }^{13}$ and these derivatives are currently undergoing preclinical studies. In the studies reported here. we evaluated the antitumor activity of LB+2907 (compound 16 in Ref 13). alone. against various cancer cells by soft agar assay and cell proliferation assay in vitro and by xenograft nude mouse model in wivo. We also investigated the effectiveness of LB 42907 in combination with paclitaxel. vincristine. cisplatin and gemcitabine in inhibiting the growth of human cancer cells using median-effect analysis.

\section{Experimental Section}

Materials. LB+2907, 1-\{[1-(1.3-benzodioxol-5-ylmethyl)-l $H$-imidazol-5-yl]methyl $;-N$-(2-methoxyethyl)- $N$-methyl-4-(1-naphthyl)-1H-pyrrole-3-carboxamide (Table 1). was synthesized at LG Life Sciences, Ltd./R\&D Park (Daejon. Korea) and its structure has been published. ${ }^{13}$ SCH66336 and R115777 were also synthesized by reported method. ${ }^{1+15}$ Paclitaxel $\left(\right.$ Taxol $\left.^{3}\right)$. vincristine and cisplatin were purchased from Sigma Chemical Co. (St. Louis. MO) and gencitabine (Gemzar ${ }^{{ }^{2}}$ ) from Eli Lilly \& Co. (Indianapolis, IN). All these compounds were dissolved in DMSO and were then diluted in culture medium immediately before use.

Cell lines. All human cancer cell lines were purchased from ATCC (Rockville. MD). NCI-H460 (large cell lung carcinoma), A549 (lung carcinoma), HCT116 (colorectal carcinoma), HT29 (colorectal adenocarcinoma), and T24 (bladder carcinoma), EJ (bladder carcinoma) cells were cultured in RPMI-1640 (GIBCO. Grand Island. NY) with $10 \%$ fetal bovine serum (FBS; GIBCO). MIA PaCa-2 (pancreatic carcinoma) cells were maintained in DMEM (GIBCO. Grand Island. NY) supplemented with $10 \%$ FBS.

Anchorage-independent soft agar assay. For soft agar assay's. the cells were seeded at various cell densities (a range of 1500 cells $/ w e l l$ to 3000 cells $/ w e l l$. depending on cell line) in 6-well tissue culture plates in 0.3\% agar (Sigma Chemical $\mathrm{Co}$.) over a $0.6 \%$ agar feed layer. as described in Ref. 13. The compound tested was included in both layers at

Table 1. Farnesyltransterase (FT) inhibitor LB42907. ${ }^{13}$

\begin{tabular}{|c|c|c|c|}
\hline \multirow{2}{*}{ Structure } & \multicolumn{2}{|c|}{$\mathrm{IC}_{\text {(1) }}(\mathrm{nM})$ for $\mathrm{FT}$} & \multirow{2}{*}{$\begin{array}{l}\mathrm{IC}_{50}(\mathrm{nM}) \\
\text { for GOT I }\end{array}$} \\
\hline & H-ras & K-ras & \\
\hline & 1.1 & 3.5 & 10,000 \\
\hline
\end{tabular}

several graded concentrations. Cells were allowed to grow at $37^{\circ} \mathrm{C}$ in an atmosphere containing $5 \% \mathrm{CO}_{2}$ for $\mathrm{l} 4$ days. and resulting colonies were counted manually. All determinations were perfonned in triplicate. at least, in two independent experiments.

Cell proliferation assay. Cancer cells were seeded into 96-ivell tissue culture plates at 500-1000 cells/well, depending on cell line, and were allowed to attach for $24 \mathrm{~h}$. A fresh medium containing the test compound alone or in combination, or a velhicle at the required concentration, was added to each well. Then. cells were incubated at $37^{\circ} \mathrm{C}$ for 5 days in an atmosphere containing $5 \% \mathrm{CO}_{2}$. Cell proliferation was measured using the colorimetric SRB assay. ${ }^{16}$ Briefly, cells were fixed in $1.3 \%$ formaldehyde solution for at least $16 \mathrm{~h}$. washed with ruming water, and were completely dried. Fixed cells were stained with $1 \%$ acetic acid containing $0.4 \%$ sulforhodamine B (SRB) dye for $2 \mathrm{~h}$ at r.t. After washing with $1 \%$ acetic acid to remove extra SRB dye, the stained dye was resolved in $10 \mathrm{mM}$ Tris buffer $(\mathrm{pH} 10.5$ ) and the plates were then read using a Molecular Devices microtiter plate reader at a test wavelength of $530 \mathrm{~nm}$ and a reference wavelength of $650 \mathrm{~nm}$. All determinations were performed in triplicate, at least. in two independent experiments.

Analysis of combination effects. The effects of the combination treatment were analyzed using the median-effect method by Chou and Talalay, ${ }^{17}$ which is specifically intended for analyzing the simultaneous cotreatment of drugs. At first, dose-effect curves were plotted for each drug to estimate its IC $C_{s !}$ as a single agent. In subsequent experiments, cells were treated with a series of dilutions of each drug individually and with two of the drugs simultaneously at a fixed ratio of doses that had been determined by individual IC $C_{\text {su }}$ S. A series of dilutions covered from one-half to 2 times the individual ICsus. From the cell proliferation data, the survival fraction ( $\mathrm{fs}$ ) was calculated by dividing the absorbance of compound(s)-treated cells by the absorbance of vehicle-treated cells. and the fraction inhibited (fi) was calculated by subtracting the survival fraction from 1. Data were calculated by the median-effect method ${ }^{17} \log (\mathrm{f} / \mathrm{fs})$ was plotted against $\log$ (dose), and then the $\mathrm{X}$ intercept (log $\mathrm{IC}_{\mathrm{iij}}$ ) and the slope $\mathrm{m}$ were calculated by the least squares method. These parameters were then used to calculate doses of the individual drugs as well as the combination required for producing varying levels of cell survival fraction ( $\mathrm{fs}=$ $0.95 .0 .90 .0 .850 .8, \ldots 0.15,0.10 .0 .05$ ) from the medianeffect equation:

$$
D_{\mathrm{fs}}=\mathrm{D}_{\mathrm{IC5})}(\mathrm{f} / \mathrm{fs})^{1: \mathrm{m}}
$$

For each level of survival fraction ( $\mathrm{fs}$ ). a $\mathrm{CI}$ value was calculated according to the equation:

$$
\mathrm{CI}=(\mathrm{D})_{1} /\left(\mathrm{D}_{\mathrm{fs}}\right)_{1}+(\mathrm{D})_{2} /\left(\mathrm{D}_{\mathrm{fs}}\right)_{2}+\alpha(\mathrm{D})_{1}(\mathrm{D})_{2} /\left(\mathrm{D}_{\mathrm{fs}}\right)_{1}\left(\mathrm{D}_{\mathrm{fs}}\right)_{2}
$$

where (D) ${ }_{1}$ and $(\mathrm{D})_{2}$ are the individual doses of the combination required to produce the survival fraction $(\mathrm{fs})$, and $\left(D_{i s}\right)_{1}$ and $\left(D_{i s}\right)_{2}$ are the doses of the individual drugs. when used alone, required to produce the survival fraction (fs). 
Also, $\alpha=1$ or 0 when the drugs are assumed to be mutually nonexclusive or mutually exclusive. respectively. The $\mathrm{CI}$ values were plotted as a function of the inhibited fraction (fi). In this method, synergy is indicated when $\mathrm{CI}<1$. antagonism is indicated when $\mathrm{CI}>1$, and additivity is indicated when $\mathrm{CI}=1 .{ }^{17}$ All related calculations were performed using the CalcuSyn program purchased from Biosoft (Cambridge, UK).

In vivo efficacy studies using xenograft nude mouse models. Human cancer cells were detached by trypsin. which was neutralized by addition of culture medium containing serum. Cells were collected by centrifugation and washed once in HBSS. Cell suspension was adjusted to a final concentration of $\mathrm{I} \times 10^{7}$ cells $/ 0.1 \mathrm{~mL}$ of HBSS. Athymic female nude mice (BALB/c AnNcrj-nu/nu: Charles River Laboratories. Japan; 5-7 weeks old) were subcutaneously injected with EJ, A549. NCI-H460 or MIA PaCa-2 cancer cells at $1 \times 10^{7}$ cells/mouse into the flank at least $\mathrm{I}$ week of acclimation period after arrival from vendor. Once palpable. the size of tumor was measured in three dimensions every three days and the volume was calculated by using the equation, $V=1 / 6 \times \pi \times L \times W \times H(V$, volume; $L$, length; $W$. width: $H$. height). When the tumor reached a volume of approximately $100 \mathrm{~mm}^{3}$. mice were randomized and separated into control and treatment groups (n $=5$ to 10 each) and it was assigned as day 0 . For oral administration. LB42907 was mixed with 10 volume of hydroxyl-propylbetacyclodexatrin (HPCD) and co-precipitated, which was dissolved in $0.05 \mathrm{~N} \mathrm{HCl}$. Treatment with LB42907 at the dose level of 40 or $60 \mathrm{mg} / \mathrm{kg}$ was initiated on day 1 and continued twice daily (bid) by gastric gavage for upto 30 days. Dose level of $100 \mathrm{mg} / \mathrm{kg}$ was included for MIA PaCa2 xenograft model. Control animals received vehicle, $0.05 \mathrm{~N}$ $\mathrm{HCl}$.

\section{Results}

LB42907, a potent and selective FT inhibitor, inhibits colony formation and proliferation of human cancer cell lines in vitro. LB42907 is a novel. potent and selective FT inhibitor (Table 1: compound 16 in Ref. 13). It has been previously shown that LB42907 inhibits the farnesylation of $\mathrm{H}-\mathrm{Ras}$ and $\mathrm{K}$-Ras proteins in vitro with $\mathrm{IC}_{\mathrm{sij}} \mathrm{S}$ of $1.1 \mathrm{nM}$ and $3.5 \mathrm{nM}$. respectively. whereas it inhibits geranylgeranyl transferase I (GGT I) with IC si) $_{\text {1) }}$ of $10 \mu \mathrm{M} .^{13}$ LB42907 also efficiently blocked the post-translational processing of $\mathrm{H}$ Ras protein in a ras-transformed rat 2 cell (data not shown).

In order to investigate the antitumor activity of LB 42907 . the effectiveness of LB42907. alone, in vitro and in wo and in combination with other chemotherapeutic drugs. against human cancer cell lines was examined. First, we evaluated the in vitro antitumor activity of LB42907 against human cancer cell lines by anchorage-independent soft agar assay and cell proliferation assay. Two lung (NCI-H460 and A549). two colon (HCT116 and HT29). two bladder (T24 and EJ). and one pancreas (MIA PaCa-2) human cancer cell lines were used in the soft agar assay. Cells were seeded in 6-well plates in an agar layer containing LB42907 and were grown for 14 days. As shown in Table 2, LB42907 displayed highly potent inhibitory activity against the anchorageindependent growths of all human cancer cells tested in the soft agar. which was comparable to other FT inhibitors, SCH66336 or R115777. The antiproliferative activity of LB42907 was also assessed in NCI-H460, A549 and HCTII6 using a colorimetric SRB assay. Cells were plated into 96well plates and were exposed to the drug continuously for 5 days. Table 3 shows the IC $\mathrm{I}_{50 \mathrm{~S}}$ of LB 42907 toward efficiently inhibiting the gronth on plastic of different human cancer cells, which were later used for combination experiments.

LB+2907 is a potent antitumor agent in the human xenograft nude mouse models. In wivo efficacy of LB 42907 was investigated in tumor xenograft mouse models. EJ, A549. NCI-H460. and MIA PaCa-2 cells were implanted subcutaneously in nude mice. and when the tumors reached approximately $100 \mathrm{~mm}^{3}$, the mice were randomized and treated either with vehicle or LB42907 as described in Experimental Section. A bid dosing schedule for LB42907 was determined from plasma pharmacokinetics in mice (data not shown). Oral administration of LB42907 at doses of 40 and $60 \mathrm{mg} / \mathrm{kg}$ twice daily to nude mice bearing EJ, or A549 tumors induced tumor regression during the 12 consecutive days of administration (Fig. 1A and B): $31 \%$ regression in EJ tumors at $60 \mathrm{mg} / \mathrm{kg}$ on day 12 and $7 \%$ and $20 \%$ regression in A549 tumors at $40 \mathrm{mg} / \mathrm{kg}$ and $60 \mathrm{mg} / \mathrm{kg}$ on day 9. respectively. In EJ tumors. $93 \%$ growth inhibition was achieved at $40 \mathrm{mg} / \mathrm{kg}$. LB42907 also suppressed the growth of NCI-H 460 tumors by $36 \%(40 \mathrm{mg} / \mathrm{kg})$ and $49 \%(60 \mathrm{mg} /$ $\mathrm{kg}$ ) after the 15 days of administration (Fig. 1C). Similarly. it

Table 2. Effect of LB42907 and other FT inhibitors on anchorage-independent growth of human cancer cells

\begin{tabular}{|c|c|c|c|c|c|}
\hline \multirow{2}{*}{ Cell line } & \multirow{2}{*}{ Tumor type } & \multirow{2}{*}{ Ras mutation } & \multicolumn{3}{|c|}{$\mathrm{IC}_{\mathrm{s}_{0}}(\mathrm{nM})$} \\
\hline & & & LB 42907 & SCH66336 & R115777 \\
\hline NCI-H460 & Human lung & K-Tas & 15 & 75 & 5 \\
\hline$A 549$ & Humnan lung & K-Tas & $<1$ & 5 & $<1$ \\
\hline HCT116 & Human colon & K-Tas & 11 & 50 & 6 \\
\hline HT29 & Human colon & Wild-type & 13 & $\mathrm{~N} / \mathrm{D}^{*}$ & $\mathrm{~N} / \mathrm{D}^{*}$ \\
\hline $\mathrm{T} 24$ & Human bladder & H-ras & $<1$ & 5.5 & $<1$ \\
\hline EJ & Human bladder & H-Tas & 1 & $N / D^{*}$ & $\mathrm{~N} / \mathrm{D}^{*}$ \\
\hline MLA Paca-2 & Human pancreas & K-Tas & 15 & 32 & $\mathrm{~N} / \mathrm{D}^{*}$ \\
\hline
\end{tabular}

*N:D; not determined 
Table 3. Eliects on the proliferation of cancer cells in vitro of LB42907 and four other drugs

\begin{tabular}{lccccc}
\hline \multirow{2}{*}{ Cell line } & \multicolumn{5}{c}{$\mathrm{IC}_{\text {50 }}(\mathrm{nM})$} \\
\cline { 2 - 6 } & LB42907 & paclitasel & vincristine & cisplatin & gemeitabine \\
\hline NCI-H460 & 368 & 5 & 4 & 29877 & 16 \\
A549 & 7 & 1 & 3 & 4225 & 28 \\
HCT116 & 70 & 1 & 3 & 3477 & 8 \\
\hline
\end{tabular}

(A)

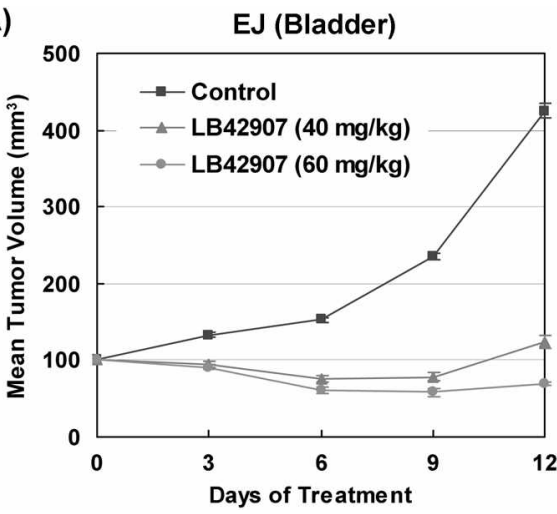

(C)

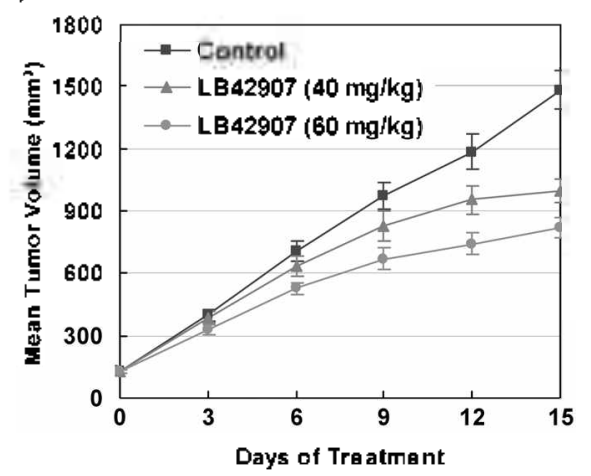

(B)

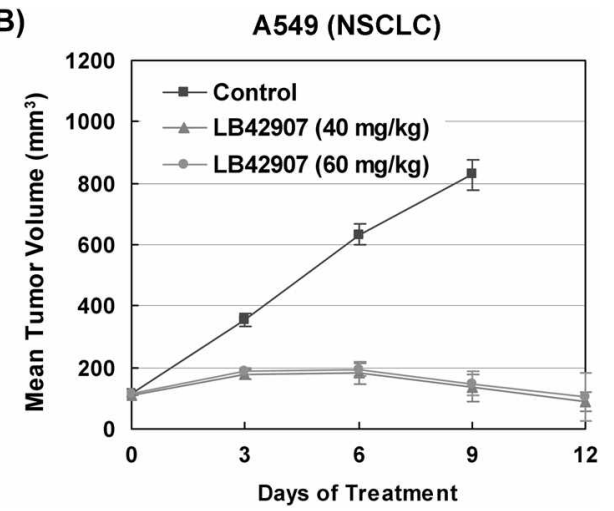

(D)

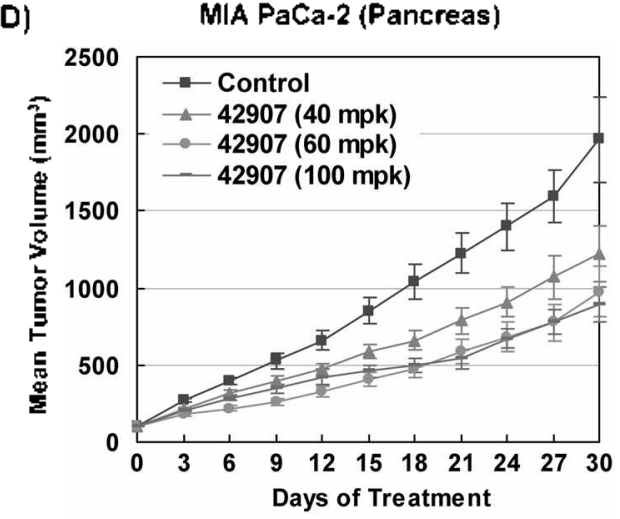

Figure 1. I $\mathrm{l}$ vivo efficacy of LB42907 $\mathrm{m}$ human tumor Xenograft models. Cells were miected subcutaneously into the flank of nude mice as described in Experimental Section. Oral administration of LB42907 was initiated after tumor volume reached approximately $100 \mathrm{mmm}^{3}$. Mean tumor volume of each group was plotted vs days of treatment. Standard errors of the mean are indicated as error bars. LB 42907 induced tunnor regression in EI bladder (A) and A549 lung (B) cancer models. Tumor growth inhibition was observed in NCI-H460) lung (C) and MIA PaCa-2 pancreas (D) cancer models.

reduced the growth of MIAPaCa- 2 by $40 \%$ ( $40 \mathrm{mg} / \mathrm{kg}$ ). $53 \%$ $(60 \mathrm{mg} / \mathrm{kg})$ and $57 \%(100 \mathrm{mg} / \mathrm{kg})$ during 30 days of treatment (Fig. 1D). In all xenograft models tested in the present study. LB42907 demonstrated a significant antitumor activity in vivo in a clear dose-dependent manner. Apparent change in body weight was not observed for LB42907 administration (data not shown). In wivo efficacies appeared to be well correlated with the in vitro cell growth inhibitory activities (Table 2 and 3 ).

Antitumor efficacy of combination treatment in vitro. We next examined the effectiveness of LB42907 in combination with paclitaxel. vincristine cisplatin and gemcitabine in three cancer cell lines using a colorimetric SRB assay. First. using the median-effect analy'sis the dose-effect plots (log (dose) vs $\log (\mathrm{fi} / \mathrm{fs}))$ were generated to determine the parameters. including their potency $\left(\mathrm{IC}_{\mathrm{Sij}}\right)$, with correlation coefficients (r value) of 0.96 or greater, indicating a good linear relationship. The $\mathrm{IC}_{\mathrm{sil}}$ are shown in Table 3. All cytotoxic drugs were active in inhibiting cancer cell proliferation. with $\mathrm{IC}_{s i \mathrm{~S}}$ ranging from $\mathrm{I} \mathrm{nM}$ to $-30 \mu \mathrm{M}$. Next, combinations of LB 42907 and other chemotherapeutic drugs were evaluated against NCI-H460. Cells were simultaneously treated with both dnugs for 5 days. as described under Experimental Section. Cytotoxicity was evaluated and each $\mathrm{CI}$ value was calculated. The results are shown in Figure 2. The $C I$ values remained $<1$ over most fraction inhibited (fi) ranges. indicating that LB42907 synergized with all four of the cytotoxic drugs tested to inhibit the proliferation of the NCI-H460 cell. In particular, the combination of LB42907 and paclitaxel demonstrated the lighest level of synergism over the entire range of cytotoxicity (fi): the CI value calculated was $0.31 \pm 0.018(\mathrm{SD})$ at $50 \%$ cytotoxicity (fi $=$ 0.5 ). under the assumption that the two drugs were mutually exclusive. Combination with vincristine or gemcitabine also 
(A)

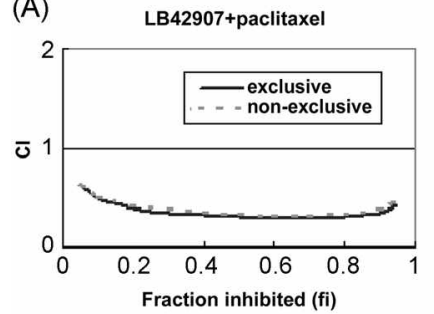

(B)

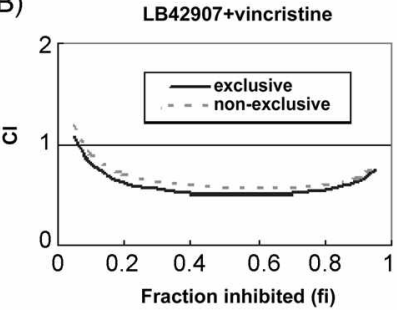

(C)

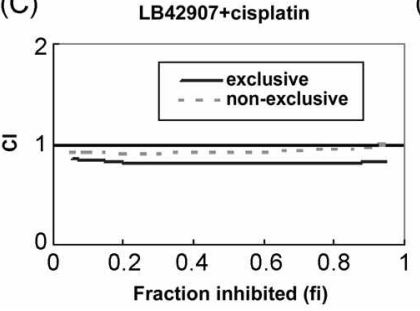

(D)

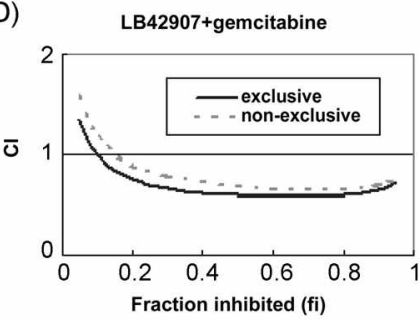

Figure 2. Eftects of combining LB42907 with paclitaxel (A), vincristine (B), cisplatin (C), and gemcitabine (D) against NCI-H460 cells The data were analyzed using the median-eftect method. Results in each panel are representative of three separate experiments.

(A)

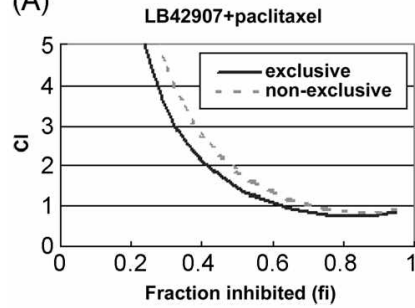

(B)

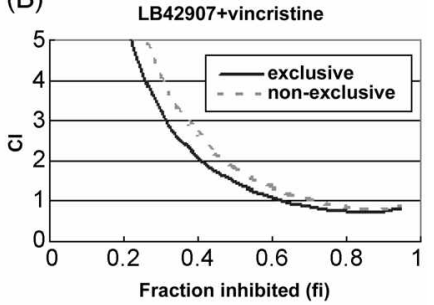

(C)

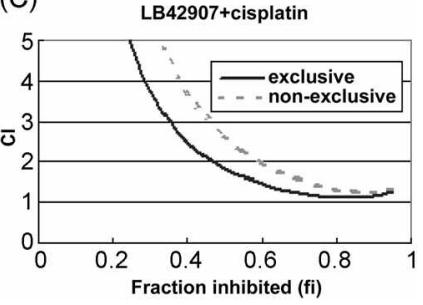

(D) LB42907+gemcitabine

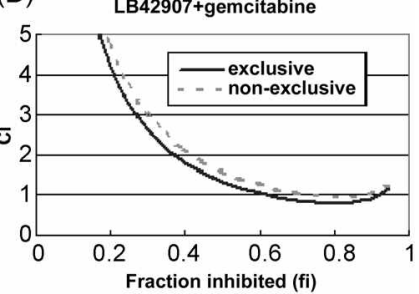

Figure 3. Effects of combining LB42907 with paclitaxel (A), vincristine (B), cisplatin (C), and gemcitabine (D) against A549 cells. The data were analyzed using the medjan-effect method. Results in each panel are representative of three separate experiments.

(A)

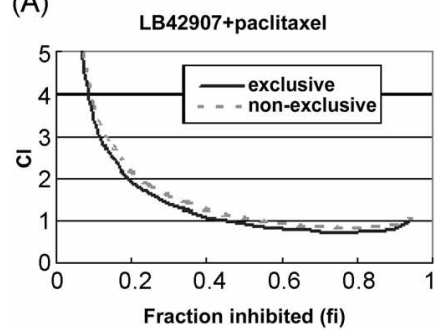

(B)

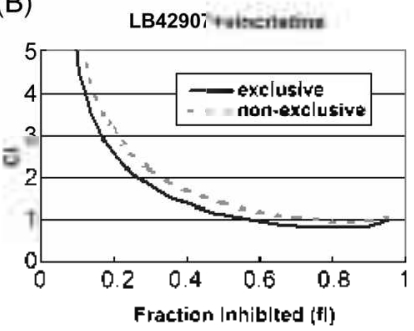

(C)

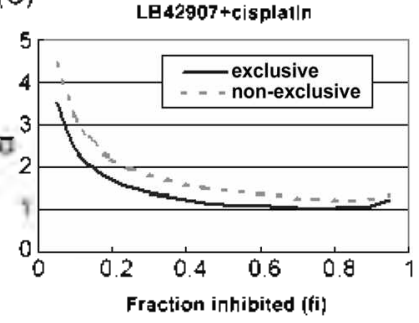

(D)

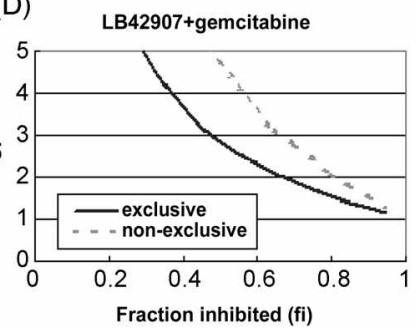

Figure 4. Effects of combining LB42907 with paclitaxel (A), vincristine (B), cisplatin (C), and gemcitabine (D) against HCT1 16 cells. The data were anlyzed using the median-ettect method. Results in each panel are representative of three separate experiments.

resulted in good synergism of action (CI $=0.50 \pm 0.034$ or $0.59 \pm 0.040$ at $50 \%$ cytotoxicity. respectively). although they did tend to have relatively decreased synergistic effects at very low levels of cytotoxicity (fi $<0.1$ ). A slight synergism. close to additivity, was observed in the combination of LB42907 and cisplatin (CI $=0.80 \pm 0.042$ at $50 \%$ cy'totoxicity).

To compare these results with those obtained with other cancer cell lines. similar combination experiments and $\mathrm{CI}$ determinations were also performed with A549 and HCT116 cells. as detailed in Figure 3 and Figure 4. respectively. When A549 cells were simultaneously exposed to LB42907 and paclitaxel. vincristine. or gemcitabine for 5 days. each combination treatment resulted in a pronounced antagonistic effect (Fig. 3A. B. and D, respectively). The CI values of these combinations were $>1$ over much of the fraction inhibited (fi) range. On the other hand the $\mathrm{CI}$ values consistently decreased below 1 at a range of $70 \%$ to $90 \%$ cytotoxicity: $\mathrm{CI}=0.75 \pm 0.034$ for combination with paclitaxel. $\mathrm{CI}=0.74 \pm 0.030$ for vincristine. and $\mathrm{CI}=0.79 \pm$ 0.068 for gemcitabine all at $80 \%$ cytotoxicity. Combination with cisplatin produced an antagonistic effect over the entire range of cytotoxicity (Fig. 3C). These results show that a combination treatment on the A549 cell resulted in antagonisn with a tendency of mild synergy over the range of relatively high cytotoxicity levels. In the HCT116 cell, a combination of LB+2907 and paclitaxel displayed either more than additive or less than additive effects. depending on the range of cytotoxicity (antagonism at cytotoxicity $<50 \%$ and synergism at $50 \%$ or higher cytotoxicity with CI $=0.71 \pm 0.040$ at $75 \%$ cytotoxicity: Fig. 4 A). A combination involving vincristine showed effects similar to those of paclitaxel though it exhibited a mild șinergistic effect (CI = $0.83 \pm 0.034$ at $75 \%$ cytotoxicity: Fig. 4B). Mild antagonism. close to an additive effect. was obtained over a wide range of cytotoxicity when combined with cisplatin. while complete and strong antagonism over the entire range of cytotoxicity was observed in the case of LB42907 combined with gemcitabine (Fig. $4 \mathrm{C}$ and D, respectively). These results show that the effects of combining LB42907 with other cytotoxic drugs on the HCT 116 cell were dependent on the class of the combined drugs and/or on the level of cytotoxicity. Taken together. combination experiments demonstrate that LB42907 markedly șynergized with paclitaxel. vincristine. and gemcitabine in the NCI-H460 cell while displaying moderate șinergism with cisplatin. but it partially sensitized or antago- 
nized the HCTI16 and A549 cells to those drugs. depending on the level of cytotoxicity and the class of the drug.

\section{Discussion}

Oncogenic Ras proteins play a critical role in intracellular signaling events mediating the unregulated cellular proliferation and tumor growth. which require plasma membrane localization through the process of farnesylation of Ras proteins. Inhibition of the farnesylation of Ras protein is an attractive strategy for anticancer therapy. Numerous specific inhibitors of farnesyltransferase have been reported to show a broad spectrum of antitumor activity

The studies reported here demonstrate that the novel FT inhibitor LB 42907 has a potent antitumor activity in vitor. proven by an anchorage-independent colony formation assay and a cell proliferation assay. Furthermore, LB42907 induces marked tumor regression of human $\mathrm{T} 24$ (bladder) and A549 (lung) xenografts when administered at a dose of 40 or $60 \mathrm{mg} / \mathrm{kg}$ twice daily. In contrast, NCI-H460 (lung) and MIA PaCa-2 (pancreas) tumors are less sensitive to the treatment of LB 42907 , displaying approximately $50 \%$ reduction of tumor gronth at a dose of $60 \mathrm{mg} / \mathrm{kg}$. In EJ and HCTll6 initiation xenograft models where cancer cell injection is immediately followed by drug administration. LB42907 also exhibited potent suppressive activity against tumor growth, which was comparable to SCH66336 when examined in parallel (data not shown). In vitro and in wivo studies indicate that $\mathrm{LB}+2907$ has a broad and potent antitumor activity. Surprisingly, LB 42907 alone is capable of inducing regression of human bladder and lung tumor xenografts expressing oncogenic $\mathrm{H}$-ras and $\mathrm{K}$-ras, respectively. There have been only few examples reported that FT inhibitor could induce tumor regression in preclinical study: FT inhibitors SCH66336 and L744832 induced tunor regression in mouse ras transgenic models ${ }^{18.19}$ while ER51785 has induced tumor regression in a human bladder tumor (H-ras mutation) xenograft in nude mouse ${ }^{3 i j}$ To our knowledge therefore this is first evidence to show tumor regression of human tumor bearing K-ras mutation induced by FT inhibitor mono-treatment in senograft model. The mechanism of tumor regression by LB42907 remains to be elucidated. It might be possible that LB42907 alone can induce efficiently apoptosis of human tumor cells in wo as well as in vitro since some kind of FT inhibitors can induce apoptosis under certain condition though. ${ }^{1,311.33}$ It would be worth exploring how far LB42907 could be cytotoxic with specificity against various human cancer cells.

LB42907 exhibited antiproliferative activity in all cell lines tested. regardless of their ras mutational status: LB42907 inhibits the growth of cell lines harboring the wild-type ras as well as the $\mathrm{K}$-ras mutation and $\mathrm{H}$-ras mutation. indicating that the cell sensitivity to LB42907 is not probably correlated with the ras mutation. which is consistent with other studies. ${ }^{2+15}$ It has been reported that some cells expressing mutant $\mathrm{K}$-Ras protein are relatively sensitive to FT inhibitors. while others with mutant $\mathrm{K}$-ras are resistant to FT inhibitors. probably because K-ras and N-ras are alternatively prenylated by geranylgeranyl transferase (GGT I) in cells treated with FT inhibitors. Therefore. the mutational status of K-ras and N-ras cannot be used to predict the sensitivity of cancer cells to FT inhibitor treatment ${ }^{26.28}$ Furthermore, it has been reported that cancer cells bearing wild-type 053 are more sensitive to FT inlibitor treatment with induction of $\mathrm{p} 21$ expression and Gl block. ${ }^{2 y}$ In other reports. however, the presence of a wild-type p 53 did not appear to significantly enlance the sensitivity of cells to an FT inhibitor. ${ }^{12.31}$ The results of our study indicate that the antitumor activity of LB 42907 is probably not correlated with p53 mutational status because similar activity was observed in cell lines harboring wild-type p53 (NCI-H460, A549. and HCT116) and mutation (HT29, T24, and MIA PaCa-2) of p53, though further investigation is needed.

The effectiveness of combining LB42907 and one of the four different anticancer drugs was investigated in witro against NCI-H460. A549, and HCT116. The conventional anticancer drugs that were tested included two antimitotic microtubule-binding agents (paclitaxel and vincristine), a DNA damaging agent (cisplatin). and an antimetabolite (gemcitabine). The present study demonstrates that LB42907 produced significant synergistic effects when combined with any one of the selected drugs over a broad range of drug concentration in the NCI-H460 cell. We observed that the activity of LB42907 simultaneously treated in combination was 1) cell line-specific, 2) dose-dependent in terms of cytotoxicity. and 3) drug-dependent.

First. LB42907 markedly synergized with most anticancer drugs tested in this study in the NCI-H460 (lung, K-ras) cell. In the A549 (lung. K-ras) and HCTI16 (colon. K-ras) cells, however, the effects varied from strong antagonism to partial synergism, depending on the level of cytotoxicity and the class of drug: these results will be discussed in detail later in this paper. It is well known that the effects of combining anticancer drugs with an FT inhibitor vary depending on the cell line the drug. and the schedule. Several authors have demonstrated synergistic or increased cytotoxic effects from the combination of FT inhibitors (such as SCH66336. L744832. ER-51785 and RPR-115135) with other anticancer drugs (such as paclitaxel and cisplatin) in tumor types of the pancreas. prostate breast. colon. lung. and bladder. $^{11.12 .210 .31 .323}$ It has been recently reported that synergism induced by the use of a combination of drugs was most significant when SCH66336 followed treatment with paclitaxel or cisplatin while only a partial synergistic effect was observed when SCH66336 was incubated simultaneously with cisplatin. ${ }^{1,11,2,3 i}$ Also, when combined with gemcitabine in NSCLC cell lines. SCH66336 failed to show synergism. regardless of the schedule. ${ }^{11.311}$ Based on these results. it would seem probable that $\mathrm{SCH} 66336$. when used in combination with other drugs. affects cell sensitivity mainly in a drugdependent manner rather than a cell line-dependent manner. It is notable however, that LB 42907 produced synergistic cytotoxicity mainly in a cell line-specific manner. which is somehow different from the observed effects of SCH66336. 
another FT inhibitor. Interestingly. there was an inverse correlation between intrinsic sensitivity to LB42907 and the occurrence of synergism. which was observed in $\mathrm{NCl}-\mathrm{H}+60$ $\left(\mathrm{LB}+2907 \mathrm{IC}_{50}=368 \mathrm{nM}\right), \mathrm{A} 549\left(\mathrm{LB} 42907 \mathrm{IC}_{50}=7 \mathrm{nM}\right)$ and HCT116 (LB+2907 IC $5070 \mathrm{nM})$. In addition, it will be worth exploring the potential effects of varying the drug schedules since a line of evidence has revealed that the effects caused by conbining an FT inhibitor and another cytotoxic drug are frequently sequence-dependent as mentioned previously.

Second. the effect of combining LB+2907 with cytotoxic drugs in A549 and HCT 116 cells was dependent on the level of cytotoxicity, which in turn corresponds to the drug concentration. Notably. our study revealed that antagonism was usually demonstrated in low levels of cytotoxicity, while mild synergism was consistently produced in relatively higher levels of cytotoxicity (Fig. 3A. 3B, 3D, 4A. and 4B). This suggests that a more than additive effect can be induced by using certain dose ranges of the two drugs. if the required concentration is clinically achievable, although such a scheme needs to be carefully designed. Similarly. changes in the cytotoxicity level when SCH66336 was combined with cisplatin affected the results of combining the drugs. ${ }^{11}$ It will be of interest to investigate how much of the effect is dependent on the levels of cytotoxicity and drug concentration. It has been reported that antimitotic agent paclitaxel has different effect on cancer cells in its concentrationdependent manner: $:^{34}$ paclitaxel at very low concentrations inhibits cell proliferation without arresting cells at mitosis. In addition, we observed that $\mathrm{LB}+2907$ induced $\mathrm{G} 2 / \mathrm{M}$ cell cycle arrest in several mutant K-ras-expressing cancer cells. including NCI-H460, A549, and HCT 116 (data not shown). It has been observed that an FT inhibitor causing cell accumulation in the $\mathrm{G} 2 / \mathrm{M}$ phase efficiently sensitizes cancer cells when conbined with antimitotic drugs. ${ }^{1231,35}$ Therefore. the failure of synergism induction at low levels of cytotoxicity night be partially explained by the possibility that the low concentrations of the antimitotic drug paclitaxel used in the present combination studies induced p53. thereby causing $\mathrm{Gl} / \mathrm{G} 2$ arrest rather than mitotic arrest. which would be insufficient to enhance the sensitivity of the $\mathrm{G} 2 / \mathrm{M}$ pause and subsequent cytotoxicity with LB42907.

Third. the effect of combining LB 42907 with other drugs in A549 and HCT116 cells was also drug-dependent. In particular. our studies revealed that LB42907 partially sensitizes cells to antimitotic agents paclitaxel and vincristine. but not to the DNA-damaging agent cisplatin. Recently. Thissen $e a^{36}{ }^{36}$ reported that K-ras, but not $\mathrm{H}$-ras or rhoB binds to microtubules in a prenylation-dependent fashion. Treatment of NIH-3T3 cells expressing GFP-K-Ras with paclitaxel resulted in an accumulation of the expressed protein in intracellular locations. whereas the protein in control cells was correctly targeted to the plasma membrane. suggesting that paclitaxel exerts its antiproliferative effects through an additional mechanism. such as the disnuption of $\mathrm{K}$-ras trafficking. Therefore, it is possible that $\mathrm{LB} 42907$ can synergize more efficiently with paclitaxel. and probably with vincristine than with other classes of cytotoxic drugs in inhibiting cancer cells that express mutant K-ras. The synergistic effect of FT inhibitors. including LB42907. might therefore be somewhat dependent on K-ras mutational status. especially when combined with paclitaxel.

In summary, the studies presented here show that an orally bioavailable FT inhibitor LB42907 exhibits a potent antitumor activity in wino as well as in witro. especially LB 42907 induced marked regression of human tumors in wio. Combination of LB42907 with other chemotherapeutic drugs resulted in significant antitumor activity in vitro, in a celldependent manner. The mechanism responsible for the antitumor effects noted here remains to be elucidated. Nonetheless, the present study provides several important observations related to the characterization of the activity. and also indicates that FT inlubitor LB42907 alone and in combination with other chemotherapeutic agents have the potential to be developed for the treatment of some cancer such as lung cancer. The synergistic effects from combination of LB 42907 and paclitaxel are observed at drug concentrations ( $10-600 \mathrm{nM}$ of LB42907 and 0.1-10 nM of paclitaxel) that are expected to be achievable in wivo. Evaluation of LB 42907 alone and in combination with other drugs could be extended against other tumor types and with other drug schedules Further in vitro and in wivo preclinical studies are warranted.

\section{References}

1. Barbacid. M. Amm. Rev Biochen 1987.56.779.

2. Bos. J. L. Cancer Res. 1989. $19,4682$.

3. Lowy, D. R.; Willumsen. B. M. Amu. Rev Biochem. 1993. 62. 851.

4. Cox. A. D: Der. C. J. Crit. Rev Oncoge 1992.3. 365.

5. Gibbs. I. B.: Olift. A.: Kohl. N. E. Cell 1994. 77. 175.

6. Rowinsky. E. K.: Windle. T. T.: Von Hoff. D. J. Clin. Oncol 1999. 17. 3631 .

7. Prendergast. G. C. Lancet. Oncol. 2000, 1.73.

8. Caponigro, F.: Casale, M; Bryce. J. Expent. Opin. Investig. Drugs. 2003. 12.943

9. Head. J. E.: Tohnston. S. R. Expert. Opin. Emerg. Lrugs. 2003. 8. 163.

10. Adjei, A. A.: Croghan. G. A.: Erlichman, C.: Marks, R. S.: Reid, J. M.; Sloan, J. A.; Pitot, H. C.: Alberts, S. R.; Goldberg. R. M. Hanson, L. J.; Bruzek, L. M.; Atherton, P. at al. Clin. Cancer: Res. 2003. 9.2520

11. Adjei. A. A.: Davis. I. N.: Bruzek. L. M.: Erlichmant. C.: Kaufinatn. S. H. Chin. Concer Res. 2001. 7. 1438.

12. Shi, B.: Yaremko. B.: Hajian, G.: Terracina. G.: Bishop, W. R: Liu. M. Nielsen, L. L. Cancer Chemother Pharmacol. 2000, 46. 387.

13. Lee. H.: Lee. J.: Lee. S.: Shin1. Y.: Tutg. W.: Kim. J. H.: Park. K.: Kiml. K.: Cho. H. S.: Ro. S.: Lee. S.: Jeong. S. W.: Choi. T: Chun1g. H. H.: Koh. J. S. Bioorg. Med Chent Lett. 2001. 11.3069.

14. Njoroge, F. G.: Taveras. A. G.: Kelly, J.: Remiszewski. S.; Mallams, A. K.: Wolin, R: Afonso, A.; Cooper, A. B.; Rane, D. F; Liu, Y. T.: Wong. J.: Vibulbhan. B. et al J. Med. Chem 1998, 11,4890 .

15. WO $9716443 \mathrm{Al}$

16. Skehan1. P.: Storeng. R.: Scudiero. D.: Monks. A.: McMahon1. J.: Vistica. D.: Warren. T. T.: Bokesch. H.: Kerney. S.: Boyd. M. R. J. Nat. Cancer Inst. 1990, 82, 1107

17. Chou. T. C.: Talalay. P. Adv Enzyne Regul. 1984. $22,27$.

18. Liu, M.; Bryant, M. S: Chen. J.: Lee. S: Yaremko, B.: Lipari, P: Malkowshi. M.: Ferrari. E.: Nielsent. L.: Prioli. N.: Dell. T.: Sinhla. 
D. etal Cancer Res. 1998.58 .4947$.

19. Kohl. N. E.: Omer. C. A.: Conner. M. W.: Anthony. N. J.: Davide. J. P.: deSolms. S. J.: Giuliani. E. A.: Gomez. R. P.: Graham. S. L: Hamilton, K.: Handt. L. K.: Hartman. G. D. et al. Nat. Med. 1995. 1,792 .

20. Nakamura, K: Yamaguch, A.: Namiki, M.: Ishihara, H: Nagasu, T.: Kowalczyk. J. J.: Garcia. A. M.: Lewis. M. D.: Yoshimatsu. K. Oncol. Res. 2000. 12.477.

21. Lebowitz. P. F.: Sakamuro. D.: Prendergast. G. C. Cancer Res. $1997,57,708$

22. Barrington. R. E.: Subler. M. A.: Rands, E: Omer. C. A.: Miller, P. I.: Hundley: J. E.: Koester. S. K: Trover, D. A.: Bearss, D. I.: Conner. M. W.: Gibbs. J. B.: Hamilton. K. et al. M fol Cell Biol. 1998. 18.85 .

23. Du. W.: Liu. A.: Prendergast. G. C. Cancer Res. 1999. 59.4208.

24. Nagasu. T: Yoshimatsu. K.: Rowell. C : Lewis, M. D.: Garcia, A. M. Cancer Res. 1995, 55.5310.

25. Sepp-Lorenzino. L.: Ma. Z.: Rands. E: Kohl N. E.: Gibbs, J. B.: Olitt. A.: Rosen. N. Canter Res. 1995. 55. 5302.

26. James. G.: Goldstein. J. L.: Brown. M. S. Proc. Natl Acad. Sci. LS. 1 1996, 93, 4454

27. Rowell, C. A; Kowalezyk J. I.; Lewis. M. D.: Gareia, A. M. J.
Biol. Chem. 1997.272. 14093.

28. Whyte. D. B.: Kirschmeier. P.: Hockenberry. I. N.: Nunez-Oliva. I.: James. L.: Catino. J. J.: Bishop. W. R.: Pai. T. K. J. Biol Chent 1997. 272,14459

29. Sepp-Lorenzino L.; Rosen. N. J. Biol. Chem. 1998, 273. 20243

30. Loprevite, M.: Favoni, R. E.; De Cupis, A.; Scolaro, T.; Semino. C.: Mazzanti. P.: Ardizzoni. A. Oncol. Rep. 2004. 11. 407.

31. Moasser. M. M.: Sepp-Lorenzino. L:: Kohl. N. E.: Oliff. A.: Balog. A.: Su. D. S.: Danishefsky. S. J.: Rosen. N. Prox. Natl. Acad Sci. LS. 1998, 95, 1369.

32. Russo. P: Malacarne, D; Falugi. C: Trombino, S.: O'Connor, P. M. Int. J. Cancer 2002, 100. 266.

33. Sun. T.: Blaskovich. M. A.: Knowles. D.: Qian. Y: Ohkanda. J. Bailey. R. D.: Hamilton. A. D.: Sebti. S. M. Cancer Res. 1999. 59. 4919.

34. Giannakakou, P.; Robey: R.: Fojo. T.; Blagosklonny: M. V. Oncogene 2001. 20,3806

35. Ashar. H. R.: James, L.: Gray: K. Carr, D.: MoGuirk, M.: Maxwell, E.: Black. S.: Armstrong. L.: Doll. R. J: Taveras. A. G.: Bishop. W. R.: Kirschmeier. P. Exp. Cell Res 2001. 262. 17.

36. Thissen. J. A.: Gross. T. M.: Subramanian. K.: Mever. T.: Casey. P. J. J. Biol. Chem 1997. 272, 30362. 